\title{
Remaining Flexible to Seize Opportunities Amidst Uncertainties
}

As Huawei evolves from a follower into an industry leader, a new challenge it faces is how to manage uncertainties. The ICT industry is full of change and uncertainty, and a moment of hesitation will cause any company to fall behind. The consequences will be more serious if that company is happy with the status quo, and refuses to make progress or listen to criticism.

The more uncertain the future is, the more opportunities there are in store. Uncertainty is exactly where profits stem from. The history of hightech companies shows that a major determiner of market value is the strategic value of growth opportunities amidst uncertainties. According to modern finance theories, a company's strategic value depends on the flexibility with which it invests in opportunities amidst uncertainties. The value of such flexibility can be interpreted and evaluated by the real options theory.

In the face of a highly uncertain future, making a strategic decision is different from making a bet. When making a future-oriented strategic decision, Huawei does not bet everything it has on a single opportunity this is too risky. Betting everything on a single opportunity is what small companies do, because they lack money to invest in anything else. Huawei is a large company, and it is increasing investment in research along multiple paths in multiple waves. Only when things become clearer will it dedicate a large team to the area it has selected. The word "failure" is not in the vocabulary of Huawei explorers. Research and innovation on

(C) The Author(s) 2019

W. Huang, Built on Value, https://doi.org/10.1007/978-981-13-7507-1_3 
uncertainties are what scientists are most interested in, but they need to be confined within boundaries and serve the company's core business. Technological innovation without boundaries can take company strategy in the wrong direction.

The company needs to ramp up investment in research on uncertainties. It should also develop the ability to distinguish between businesses of certainty and those of uncertainty, create certainty out of uncertainty, and make the elements of certainty standardized, process-based, and automated to achieve higher efficiency and better results. These are the major tasks of management transformation.

From the perspective of strategic value management, this chapter thoroughly discusses how Huawei remains flexible to seize opportunities amidst uncertainties and face future challenges.

\subsection{Maintaining Flexibility When Investing in Projects of Uncertainty}

\subsubsection{Never Putting All Eggs in One Basket When Making Strategic Decisions}

When we decide to move in a certain strategic direction, we need to invest strategically in an opposing direction to guard against potential risks and help to buy us some time if the strategic direction we choose turns out to be wrong. If we lack a clear direction amidst chaos, we must make balanced investments in multiple directions to guard against risks. Only when things become clearer can we dedicate a large team to the area we have selected. Despite this, we need to carefully study the areas in which we can seek international cooperation. We must not do everything on our own. Every company needs to focus on its area of expertise. (Ren Zhengfei: Speech at the Work Report of the Product Line Management Office, 2000)

When we make strategic decisions, we must not put all our eggs in one basket. It is too risky to select only one product for investment. (Ren Zhengfei: Comments to Staff of the CDMA20001 Base Station Team, 2001)

\footnotetext{
${ }^{1}$ CDMA: code division multiple access, a communications scheme that uses frequency expansion technology to form different code sequences. When the CDMA scheme is used, subscribers with different addresses can use different code sequences for multi-address connections. This mobile telephony system is applicable to ultrahigh frequencies including $800 \mathrm{MHz}$ and $1.9 \mathrm{GHz}$.
} 
No one knows how large data traffic will be in the future. In this era of massive data traffic, fixed networks will have an integral role to play. There will be plenty of market opportunities. Since we have set our strategic direction, we need to seize multiple opportunities to achieve our objectives. We cannot bet everything on a single opportunity. This is what small companies do, because they lack money to invest in anything else. Huawei is a large company with enough money, so we should dare to invest. To achieve our objectives, we can select multiple paths, develop multiple technical solutions, and move in multiple waves in our research and innovation. Similarly, in our core business, we can use multiple methods to row our boat. However, this doesn't mean we will diversify our investments, or deviate from our core business. In such a rapidly changing world, we should never rely on chance. Companies that bet everything on a single opportunity may find it hard to succeed. If they choose the wrong strategic direction, they will suffer badly. (Ren Zhengfei: Speech at the Briefing on Industry Trends and Progress in Fixed Networks, Huawei Executive Office Speech No. [2015] 109)

\subsubsection{Lavge Investment Along Multiple Paths in Multiple Waves}

As long as there is sufficient demand in the market, we must seize the opportunities it brings. Since we don't know what will happen in the market in the future, we need to compete on a wider front and must not give up easily. When things become clearer, we should immediately shift our investments to key areas. Therefore, I think we should be business or product-driven. Profitability is also important, but we must not be completely profit-driven. What we need are future opportunities. (Ren Zhengfei: Meeting Minutes of the RerD Management Committee, 2001)

We need to create a protection system to ensure the Blue Team ${ }^{2}$ is in an important position within Huawei. The Blue Team may seem irrational at times. Some of its members have the courage to think, speak, and act out in ways we are not familiar with. We should show leniency towards them after their debates with the Red Team. It's very likely that they can create a unique way forward. I can think of two examples of defensive lines that

${ }^{2}$ As part of its ongoing effort to identify potential weaknesses, Huawei employs a "Red Team and Blue Team" method of self-reflection. The Blue Team plays the role of a competitor, always challenging the Red Team and exposing its faults to help the Red Team improve. 
failed to live up to their purposes. One was the Maginot Line built by the French to protect France against Germany. The German army didn't attack the line directly, but instead attacked France through Belgium, making the Maginot Line useless. The other was the defensive line of 17 fortresses built by Japan in northeast China. This was designed to prevent the Soviet Union from attacking Manchuria, but the Japanese didn't realize that the Soviet Union would traverse the Greater Khingan Range instead. Unexpectedly, the Soviet troops had passed through the mountains and bypassed the Japanese fortresses. I think offense is more important than defense, and this means we need to value the role of the Blue Team. The Blue Team must try its best to challenge the Red Team. Even if it fails, it has to try. The success of the Three Gorges Dam would have been impossible without opposing voices. Although their role was not recognized explicitly, the design of the dam was revised based on their opinions. We must recognize the value and role of those with different ideas and welcome their input. (Ren Zhengfei: The Best Defense Is a Good Offense-Remarks at a Briefing on the Wireless Network Business, Huawei Executive Office Speech No. [2013] 232)

Greater leaders are made through practice, rather than by thinking. We need to get everyone involved in real operations. For some enterprises that emphasize scale and service, both market demand and development space are limited. Due to commoditized competition, other companies can edge in to grab market shares, and shrink that development space. However, the telecom industry is rapidly growing and it is a place where real strengths count. If you cannot deliver something advanced, and if you have no forward-looking strategy, you will quickly collapse. Many companies similar to Huawei have collapsed. Huawei is not a public company, so our top management develops strategies with an eye on the next five to ten years, without worrying about short-term gains. Therefore, we move faster than others and are more forward-looking. To make breakthroughs, we must have strategic patience. If we cannot make breakthroughs within 10-20 years, or even within our own lifetimes, we would be left in a secondary position. We are not currently betting on any particular technology or direction. Betting on a single business opportunity is something small companies do, because they don't have enough money to invest in multiple areas. Large companies have sufficient funds to advance in their core business along multiple paths in multiple waves, and can be investment-intensive to reduce the time needed to explore the direction. Of the multiple opportunities we explore, some might become major 
industry trends. We can then focus more on these opportunities and less on others. That being said, we don't need to close the door on other opportunities. We can transfer experienced managers to major fields while deploying new managers in minor fields so that they can continue to push forward. This will give us multiple perspectives. Reflecting on failures will also be helpful. Having multiple perspectives will enable us to climb to the top. In order to win battles, the US military doesn't calculate how much ammunition it uses. Some people think they waste ammunition, but in fact they are concentrating energy to advance. We also have a mechanism in place to attract talent. When our 150,000 employees work towards the same goal, we can only succeed. (Source: A Chat in the Garden with Huawei Founder Ren Zhengfei, Huawei Executive Office Speech No. [2015] 098)

For research and verification of uncertainties, we advocate multiple waves of exploration along multiple paths, with large and focused investment when things become clearer. The Blue Team should also have their physical organization. In addition, we don't make assessments based on success or failure. We must extract success factors from failed projects, affirm achievements, praise those who deserve it, and encourage ongoing exploration. The word "failure" is not in the vocabulary of Huawei explorers. (Ren Zhengfei: Dedicated to China's Century-old Dream of Revitalizing Science and Technology, Huawei Executive Office Speech No. [2016] 067)

The word "failure" is not in the vocabulary of Huawei explorers. When monkeys lived in trees, there were no paths on earth. After they evolved into human beings, they walked and left behind small zigzagging paths. Numerous explorers made the world a place with countless crisscrossing paths. No one can ever walk the entire length and breadth of the world. Those who manage to cover just one section of a long path are heroes. A total of 3.5 million ships sank along the sea route from Europe to Asia. Those who sank along with the ships were heroes of globalization. Flawed heroes are still heroes. This idea inspires people to continuously explore and make sacrifices for science. If people who have "failed" remain in our team with their experiences, we will become more mature. We should understand geniuses who might seem eccentric, and allow "black swans" to fly out of our coffee cups. We will either succeed or fail in innovation. We should boldly embrace "disruptive" ideas. Broken from the outside, eggs will be fried. Broken from the inside, peacocks will emerge. (Ren Zhengfei: Dedicated to China's Century-old Dream of Revitalizing Science and Technology, Huawei Executive Office Speech No. [2016] 067) 
There are also heroes in failed projects. We must be open-minded to accommodate more talent, and explore the future along multiple paths. Certain paths might fail, but they may well produce great people, or heroes. Flawed heroes are still heroes. We should be good at extracting success factors from failed projects. In this sense, failure will also mean success. In areas of certainty, we can assess if a person is a hero purely by the outcome he or she delivers. But in areas of uncertainty, there are heroes in failed projects as well, as long as they are good at summarizing what they've done right and what they haven't. Therefore, when assessing a person, don't jump to conclusions. Disruption is often performed by outsiders, who rarely follow the same logic as the insiders. Take old China as an example. It was two doctors, Sun Yat-sen ${ }^{3}$ and Lu Xun, ${ }^{4}$ who brought disruptive changes to the country. (Ren Zhengfei: Scale New Heights and Forge Abead into Uncharted Territory Along Multiple Paths in Multiple Waves-Key Messages of Discussions at Mobile World Congress and in Ukraine, Huawei Executive Office Speech No. [2016] 068)

Society has undergone many twists and turns. We have already touched the feet of truth. Don't always think that we fail in what we are doing. What is failure and what is success? If you walk on a path and find that it is wrong, but you tell your colleagues about it and they then try another one, this is also success. Your experience will be greatly enriched during these so-called failures. ... When assessing employees, we must not use a simple black-or-white mindset. I am referring to you guys working in research projects, not projects of certainty. (Ren Zhengfei: Speech at a Meeting with Employees of the Noah's Ark Laboratory, Huawei Executive Office Speech No. [2016] 083)

In scientific research, we must not suppress people with different opinions. This is what I mean by multiple paths. We must respect different opinions, which is necessary to make multiple paths possible. The paths we take in the future will thus become wider and wider. If we want to become a global leader, we must be open-minded. (Ren Zhengfei: Remarks at

\footnotetext{
${ }^{3}$ Sun Yat-sen (1866-1925), known as the father of modern China, was influential in overthrowing the Qing dynasty and served as the first president of the Republic of China in 1912. He started his career as a medical doctor.

${ }^{4}$ Lu Xun (1881-1936) was an important literary critic known for his sharp and unique essays on the historical traditions and modern conditions of China. He is widely considered China's greatest modern writer of the twentieth century. He received medical training in Japan between 1904 and 1906.
} 
Meetings with Huawei Fellows, Huawei Executive Office Speech No. [2016] 069)

Huawei pushes its employees through a "bottleneck". This is part of our core values. After being pushed through the bottleneck, employees can run faster and faster, propelling the Huawei "machine" to move forward. We are now making changes, so that all of you can unleash your potential and be inspired. (Ren Zhengfei: Remarks at Meetings with Huawei Fellows, Huawei Executive Office Speech No. [2016] 069)

Innovation in the future must be multidisciplinary. However, it is impossible for Huawei to have so much multidisciplinary talent, so $\mathrm{Hu}$ Houkun $^{5}$ said that we should weaken the "staff badge culture". Previously, we used the term "narrowband and high amplitude", meaning that each employee is very strong in one area, but his or her scope of knowledge is rather narrow. However, if we combine the expertise of all of our employees, we will achieve "broadband and high amplitude". How can we become multidisciplinary? Through all kinds of combinations. These measures will be how we approach research in the future. (Ren Zhengfei: Remarks at Meetings with Huawei Fellows, Huawei Executive Office Speech No. [2016] 069)

People in the first echelon may not have time to read books or corporate documents, and they might be worn out within a couple of years. So the second echelon, or the rising stars of the future as we call them, will take the baton, build on what the first echelon has achieved, and continue to press forward. From the comments posted on our Intranet, I see our younger generation is catching up and picking up the baton from the first echelon. But we still need to prepare our second echelon and recruit top students in China majoring in lasers, physics, and chemistry. Lasers are fast, and students studying lasers tend to think fast as well. Zheng Baoyong ${ }^{6}$ is one such example. The second echelon should not do exactly the same thing as the first echelon; that's not what they are there for. The second echelon should be able to identify the problems that already exist, and resolve issues that the Red Team has never thought about or has no capacity to resolve, or even issues that are very different from the Red Team's thinking. (Ren Zhengfei: Scale New Heights and Forge Abead into Uncharted Territory Along Multiple Paths in Multiple Waves-Key Messages

\footnotetext{
${ }^{5} \mathrm{Hu}$ Houkun was the Rotating CEO of Huawei at the time.

${ }^{6}$ Zheng Baoyong was an Executive Vice President of Huawei at the time.
} 
of Discussions at Mobile World Congress and in Ukraine, Huawei Executive Office Speech No. [2016] 068)

Huawei holds tight to the pipe strategy, remains open and collaborative, and aims to unite as many people as possible to explore the future direction and keep uncertainties under control. (Ren Zhengfei: Remarks at Meetings with Huawei Fellows, Huawei Executive Office Speech No. [2016] 069)

In addition to achieving success in the marketplace, we should also accomplish something in technology. On top of the more than 8 to 9 billion US dollars invested in development, we are also investing more than 3 billion US dollars in research each year. Why are we expanding our efforts into basic research? Because this is a rapidly-developing era. The whiplash pace of network progress has made it impossible for us to continue the slow practice of understanding scientific papers, conducting engineering experiments, and then developing products. Now we need to get involved in scientists' exploration and research, and think about how we can turn their research results into products. We will encourage scientists and engineers in our dozens of centers of expertise (COEs) to proactively explore, and will assure them that they don't need to be afraid of failure. In addition, we will transcend the limits of our "staff badge culture" and sponsor scientists worldwide who are moving in the same direction as us. We don't invest for a narrow purpose. As I noted at the National Academy of Sciences of Belarus, we support scientists selflessly. We don't aim to own their papers, patents, or other achievements. We simply wish to keep abreast of their progress, including both successes and failures. Similar to a lighthouse, scientists can illuminate us, and also others. We don't seek to own the lighthouses or interfere in how their research results are applied. (Ren Zhengfei: Be First to Know When Springtime Comes. Vow Not to Return Till We Reach Our Goals-Speech at an Oath-taking Rally for Reassigned Senior ReD Experts and Managers, Huawei Executive Office Speech No. [2016] 093)

\subsubsection{Absorbing the Energy of the Universe over a Cup of Coffee}

We must be more open-minded. We can exchange ideas with others in coffee houses or share ideas online to inspire the next generation of talent. (Ren Zhengfei: Speech at the Meeting with Staff from the 2012 Laboratories, Huawei Executive Office Speech No. [2012] 035) 
Our senior managers and experts are expected to attend more international conferences, and sit down for a coffee with others, aiming to find inspiration by communicating and exchanging ideas with others. After returning from conferences, they need to write down their thoughts on what they saw. They may not think this is a big deal, but what they write may inspire other people and help them succeed. They contribute if they help someone else in the company succeed. The reason we have so many strategy retreats is that we want to explore the correct strategic positioning. This is what we call "absorbing the energy of the universe over a cup of coffee". (Ren Zhengfei: The Best Defense Is a Good Offense-Remarks at a Briefing on the Wireless Network Business, Huawei Executive Office Speech No. [2013] 232)

We need to absorb the energy of the universe over a cup of coffee. Why don't our Fellows ${ }^{7}$ communicate their technological ideas with the seeds for the future, like PhDs and doctoral students? If you can have coffee with experts, why not have coffee with those seeds as well? The expense on coffee can be reimbursed. It's okay if the experts don't join Huawei. They can still contribute to humanity. By communicating with these highpotential people, we are creating a huge group of like-minded experts and exerting influence on the world. It is like creating ripples in a pond. If one Fellow makes five friends like this and each of these people has hundreds of followers, a lot of people will be influenced. Communicating with others is also an effective way to improve ourselves. We don't know what the future will look like. The network inside Huawei is very small. If our Fellows stay in the office all day and don't go out to drink coffee with others, our company may eventually fail. Scientists should not be too restricted by our attendance rules. They might not always be able to clock in and clock out at the right times if they are busy communicating with people outside the company. All in all, we must be open-minded in our management. (Ren Zhengfei: Absorbing the Energy of the Universe over a Cup of Coffee, 2014)

Huawei must strive to become a world-class company. Currently, we lack thinkers and strategists and only have generals who are good at operations. If our philosophy and direction are wrong, the better we are at

\footnotetext{
${ }^{7}$ Fellow is the highest honor for technical professionals at Huawei. This title is presented to employees who have made creative achievements in and significant contributions to products, technologies, engineering, and other domains, and have sufficient influence in the industry.
} 
operations, the more problematic things will become. So besides technical experts I hope some of you can become thinkers to help build the future world. (Ren Zhengfei: Absorbing the Energy of the Universe over a Cup of Coffee, 2014)

Our senior managers and experts need to become more open-minded, broaden their horizons, and change their narrow mindsets. They need to communicate more and drink more coffee with others. The US's IT industry is the world's most advanced. While we continue to bring in high-end experts, our senior managers and experts need to go out and communicate with their counterparts all over the world. They need to learn how to absorb the energy of the universe over a cup of coffee rather than only working hard all on their own. We attend many international conferences and forums. On these occasions, it may only take five minutes for us to get inspired and absorb a lot of energy over a cup of coffee. You won't know what the world is like if you don't change your mindset and interact with the world. Sometimes, we may be inspired by only a few words. (Ren Zhengfei: Taking a Long-term View When Making DecisionsSpeech at a Briefing by the Chengdu Research Center, Huawei Executive Office Speech No. [2014] 027)

As we move forward, it is not enough to focus only on cutting-edge technologies. We also need to cultivate a group of technology ambassadors. These "ambassadors" should be outstanding experts who not only specialize in a single domain, but also have an extensive knowledge base and strong comprehensive capabilities. While our Fellows are committed to developing new technologies, our technology ambassadors can travel around the world to have coffee with others as assistants to our Fellows and keep up with the latest trends. They can capture new information about the industry through such exchanges and interactions and bring that information back to our platform for analysis. Scientists can then discuss and analyze such information at strategy retreats. If they conclude that the direction is correct, the information discussed will become the main points of the retreats and be sent to our 2012 Laboratories. From there, the 2012 Laboratories will begin technological research for the next decade or two. After we see research achievements after a period of time, we can send them to the strategy marketing department to help with our business planning. (Ren Zhengfei: Speech at the Briefing on Industry Trends and Progress in Fixed Networks, Huawei Executive Office Speech No. [2015] 109) 
We will either succeed or fail in innovation. We should boldly embrace "disruptive" ideas. Broken from the outside, eggs will be fried. Broken from the inside, peacocks will emerge. Today, technology advances very rapidly, and uncertainties are on the rise. We are going to be deeply engaged in product development, which is part of our known and certain territory. However, in order to keep pace with the times, we need to increase our investment in uncertainties. We encourage scientists, experts, and engineers - tens of thousands of them - in our COEs to strengthen communication with the outside world in order to absorb the energy of the universe over a cup of coffee. We aim to turn our Strategy and Technology Workshop into a "Roman Square", an open platform for scientific and technological discussion, so that sparks of ideas will turn into burning fires. Our company should have ideals, and discard the mindset of calculating profits in particular areas. It is hard to plan major innovations. Staying stuck in a rut would be the easiest option, but this would keep us from seizing big opportunities. (Ren Zhengfei: Dedicated to China's Century-old Dream of Revitalizing Science and Technology, Huawei Executive Office Speech No. [2016] 067)

"Black swans" might appear but, when they do, we hope that they will appear in "our coffee cups". We must be open-minded, support scientists who are moving in the same direction as us, and understand and support geniuses who may seem eccentric. We welcome "black swans" to fly in our company; they could represent a chance to reinvent ourselves. (Ren Zhengfei: Scale New Heights and Forge Ahead into Uncharted Territory Along Multiple Paths in Multiple Waves-Key Messages of Discussions at Mobile World Congress and in Ukraine, Huawei Executive Office Speech No. [2016] 068)

We should find and support some professors with opinions different from the mainstream. Then we should create a team to follow them, and that team will become part of the second echelon. Quantum communications is a good example. Several years ago, it was widely criticized as something unrealistic and far away down the road. Look at it now. China has already done it. Can we include things like this in one of our paths as we explore the future? We must be bold in supporting people who are intelligent, including $\mathrm{PhD}$ candidates and seemingly eccentric geniuses. And we need to spot them early on, say, in universities. We can begin to support them when they are still students, but they don't have to join Huawei after graduation. If they later make inventions that can help resolve our 
problems, we can pay them for the use of these inventions. (Ren Zhengfei: Scale New Heights and Forge Ahead into Uncharted Territory Along Multiple Paths in Multiple Waves-Key Messages of Discussions at Mobile World Congress and in Ukraine, Huawei Executive Office Speech No. [2016] 068)

To absorb the energy of the universe over a cup of coffee, you don't have to bring all top experts on board or make them part of Huawei. What truly matters is their ideas. Can we set up a Thought Research Institute that mainly comprises Fellows? Fellows must be involved in multiple fields, exchange ideas with others, and be powerful sources of inspiration. This institute will be positioned to conduct research into ideas and directions, not just into technologies. Fellows should not just work on specific tasks, or just care about products. We would like them to just sit down with the right people for a cup of coffee, and share each other's inspirations to continuously generate streams of ideas. Each research center should have some budgets of their own; it's a brilliant idea. $\mathrm{Xu} \mathrm{Wenwei}{ }^{8}$ said that we will not touch content or data. That is a major direction, and it's also a brilliant idea. However, this doesn't mean we will draw a clear demarcation line. We must develop the capacity to support massive amounts of content and data, but we won't monetize them. (Ren Zhengfei: Scale New Heights and Forge Abead into Uncharted Territory Along Multiple Paths in Multiple Waves-Key Messages of Discussions at Mobile World Congress and in Ukraine, Huawei Executive Office Speech No. [2016] 068)

We need to use American bricks to build our own "Great Wall" and allow the eccentric to dance on it. We should be very open-minded when it comes to research on artificial intelligence (AI). Conducting research yourselves is also a good idea; otherwise, you won't be able to know whether you're moving in the right direction, or on which areas you should focus. There are companies who are doing better than us. We can bring in what they have made to our company. (Ren Zhengfei: Speech at a Meeting with Employees of the Noah's Ark Laboratory, Huawei Executive Office Speech No. [2016] 083)

${ }^{8} \mathrm{Xu}$ Wenwei was the Chief Strategy Marketing Officer of Huawei at the time. 


\subsection{TeChNOLOGical InNOVATion Without Boundaries Can Take Company Strategy IN THE Wrong Direction}

\subsubsection{Product Innovation Must Focus on the Core Business and Must Always Be Driven by Business Needs}

What do we mean by freedom? For us, freedom means setting rules and making things work by following the rules. For a train, freedom means traveling on the tracks and reaching its destination without being derailed. Freedom comes from awareness of the laws of nature. It is the opposite of necessity, which is the result of a lack of knowledge or mastery of the laws of nature. (Ren Zhengfei: Shifting from the Realm of Necessity to the Realm of Freedom, 1998)

We have boundaries for our research and innovation. We must only focus on our core business, or areas closely related to it. Our product innovation must always be driven by business needs. Bell Labs ultimately came apart because of its reckless innovation. Although Bell Labs specialized in communications, some of its scientists invented the electron microscope because of personal interests. Discarding the invention makes its heart ache, so Bell Labs established an organization to put the microscope into commercial use. This story tells us that technological innovation without boundaries can take company strategy in the wrong direction. Product innovation should be done within certain boundaries. Research and innovation can be a bit broad, but not boundless. We need to achieve Huawei's ideals, not the ideals of humanity. Our innovation should have boundaries. (Ren Zhengfei: Absorbing the Energy of the Universe over a Cup of Coffee, 2014)

Innovation should have boundaries. We will continue our needle-tip strategy and focus our efforts on the core business to make breakthroughs and take the lead in the era of massive data traffic. (Ren Zhengfei: Our Transformation Goals Are to Harvest More Crops and Increase Soil Fertility-Speech at the 2015 Huawei Market Conference, Huawei Executive Office Speech No. [2015] 016)

We have two decision-making systems: One is an idealistic system, which focuses on technology. The other is a realistic system of Strategy Marketing, which focuses on customer needs. We encourage fierce debate between these two systems and would like to see them reach consensus on 
product development goals. (Ren Zhengfei: Remarks at Meetings with Huawei Fellows, Huawei Executive Office Speech No. [2016] 069)

We don't know what the future information society will look like. We need to develop assumptions about it. Without correct assumptions, there will be no correct direction. Without a correct direction, there will be no correct thoughts. Without correct thoughts, there will be no correct theories. Without correct theories, there will be no correct strategies. The Thought Research Institute will explore future ideas and directions. The 2012 Laboratories will develop them into theories and then verify them. In other words, the 2012 Laboratories conducts experiments with future assumptions and ideas. No matter what, we must figure out where we should be heading. (Ren Zhengfei: Scale New Heights and Forge Abead into Uncharted Territory Along Multiple Paths in Multiple Waves-Key Messages of Discussions at Mobile World Congress and in Ukraine, Huawei Executive Office Speech No. [2016] 068)

\subsubsection{Research and Innovation on Uncertainties Must also Have Boundaries and Serve the Core Business}

We focus on our core business, with sustaining innovation at the core, complimented by disruptive innovation. On the Internet, disruptive innovation is a hot topic, but we aim to create value for the world and innovate to create greater value. We should still focus on social demand for the next five to ten years; most of our people should not be looking any further into the future. For most of our products, we should focus firmly on sustaining innovation. At the same time, we should allow a small part of our younger employees to engage in disruptive innovation: to "talk nonsense" and explore new ideas. These employees can be as disruptive as they please, but they must remain within certain boundaries. Such disruptive innovation is openly accessible, allowing sustaining innovation to continuously absorb energy from it; after disruptive innovation has grown into a strong sapling, it can turn around and absorb energy from sustaining innovation. (Ren Zhengfei: Innovating to Create Global Value-Speech at the Corporate Strategy Retreat, Huawei Executive Office Speech No. [2015] 006)

Our mission is to create value for humanity. Our innovation must serve this purpose. We must not innovate just for the sake of innovation. I think the concept of independent innovation is one-sided. We need to stand on the shoulders of giants in order to move forward. If we have to climb upward from the ground by ourselves, it could take millennia for us to 
reach our goals. To reach our goals faster, we must take advantage of all past achievements, as this will increase efficiency. ... During the course of innovation, we need to absorb as much energy as possible to save on time and resources needed to create value. Using other people's intellectual property by paying them reasonable fees is more cost-effective for us. Innovating blindly on our own is far more expensive. Every year we invest $10 \%$ of revenue in $\mathrm{R} \& \mathrm{D}$, and much of the funds are spent on purchasing intellectual property from others and on research projects that are terminated in their early stages. To be an industry leader, we must not be so narrow-minded as to throw stones on highways to stop others and develop our own unique strengths. This will harm other market players and impede global progress. This is not what we want to achieve. Our aim is to become an industry leader and contribute to the world. Then what makes a leader? Being a leader means making the world a better place, contributing to the broader architecture of global information networks, and sharing value with others. (Ren Zhengfei: Speech at a Meeting with Employees of the Legal Affairs Department, Secretariat Office of the Board of Directors, and Wireless Network Product Line, Huawei Executive Office Speech No. [2015] 015)

We need to reduce the workload that our management system has to handle, because there is beauty in simplicity. Our management system doesn't need to handle too many things. During this year's budgeting process, we won't earmark much money for product development, which is a job of certainty and needs to focus on the target and efficiency. We will increase our investment in future growth and breakthroughs in uncharted territory. An investment-intensive approach must not be used randomly. We need to review it carefully. Research and innovation on uncertainties must also have boundaries and serve our core business. We need to limit research and innovation initiatives that don't serve our core business. (Ren Zhengfei: Speech at the EMT ST Meeting on January 25, 2016, Huawei Executive Office Speech No. [2016] 054)

Our AI should be confined to our core business, and we should not pursue applications beyond them. Our AI should be bundled with our core business. Within the core business, we can invest heavily and work together to generate more ideas and unleash greater potential. I won't give you money if you deviate from our core business. Huawei will not make AI products for public use or small AI commodities. I am afraid that you might act on impulse and compare your AI with AI outside of Huawei. If I don't use your AI products, some of you may start a business with them. This will hollow our company out. If you are talented, you should 
come to work in our core business. AI products for public use are the major business of other companies, not of our company. We should not engage in this business. We can just buy such products from others after they succeed in producing them. (Ren Zhengfei: Speech at a Meeting with Employees of the Noah's Ark Laboratory, Huawei Executive Office Speech No. [2016] 083)

\subsection{Identifying and Creating Certainty Out of UnCERTAinty}

\subsubsection{The Role of a Leader: Setting a Clear Direction Amidst Uncertainties}

The uncertainty of the future poses lots of risks to us. In the face of uncertainties, managers at all levels must focus on the most important issue and the key factor that influences it, set a clear direction, control the pace, and apply huidu ${ }^{9}$ to achieve goals. We must do more self-reflection and be more alert to changes in our surroundings. This is what I mean when I say "Digging In and Widening Out". (Ren Zhengfei: Who Calls for Artillery and How Do We Provide Timely Artillery Support?-Speech at the Awards Ceremony of Sales \& Services, Huawei Executive Office Speech No. [2009] 001)

Huawei's goal of establishing committees is to make collective, highquality decisions on key issues and uncertainties in the business environment. Regarding routine business operations with relative certainty, business commanders need to make decisions to increase operating efficiency. (Source: EMT Meeting Minutes No. [2013] 009)

To deal with uncertainties, we need to identify them first. Every year, our company discusses and determines key uncertainties we face. Our strategy department and other relevant departments then study and analyze these uncertainties, work out measures to address them, and follow up on the progress of their handling. (Source: BOD Executive Committee Meeting Minutes No. [2015] 005)

In the face of economic, financial, and market uncertainties, we must systematically identify the operational, financial, and compliance risks posed to Huawei, create a corporate risk management map, and assign

\footnotetext{
${ }^{9}$ Huidu is a Chinese term used at Huawei to describe the shades of grey that exist between black and white, which implies flexibility and balance without losing sight of direction.
} 
owners for major risks. The goal is to effectively reduce the impact of uncertainties on our operations. (Source: EMT Resolution No. [2015] 013)

The external environment is changing. To become the world leader over the next five years, we need to drive further transformation in our own business domains of certainty, develop capabilities to cope with future risks, and adapt to changes in the external environment. This transformation in domains of certainty will support us in dealing with uncertainties. (Source: EMT Meeting Minutes No. [2015] 007)

We now face severe challenges in our management transformation. Most members of our transformation teams are engaged in businesses of certainty, and they should have the confidence to study the issues that Huawei faces. In Europe, why does the installation of a base station cost 20,000 Euros in certain countries, but 3000 Euros in other countries? The higher costs result from our failures to effectively manage businesses of certainty, make these businesses process-based and standardized, and consistently integrate data. These costs directly impact our bonus packages. If we eliminate these costs, then they could become bonuses for us. Doesn't that make sense? We must strive to improve in this aspect, so as to further increase our efficiency and make more contributions. This will enable our company to enter a positive cycle. Our turnkey projects are good examples. In the past, we had no clue about these projects. But things have changed: We now have a general understanding of them. In the future, we will need to study how to do better in all our business domains to make further improvements. (Ren Zhengfei: Speech at the Oath-taking Ceremony for the Third Session of the Transformation Elite Team, Huawei Executive Office Speech No. [2015] 078)

A leader must have a sense of direction. The role of a leader is not to carry a hoe or dig a trench. It's about leading the team out of difficulty and finding the right direction forward. A sense of direction is about making a definite judgment on the way forward out of uncertainties, especially when resources are limited. Of course, a sense of direction can also involve making a vague judgment that somehow helps to lead the team out of chaos. We used to follow others in the world; but in the future, we will take the lead. What should we do? Years ago, the Personal Handy-phone System (PHS) and TD-SCDMA almost killed me. Why? Because of the tough decisions I had to make. When PHS was really hot in the market, our teams said they could develop similar products within three months, and I had to decide whether to do it or not. TD-SCDMA was a similar story. That kind of anguish lasted eight years, and sometimes I wonder 
how I made it; it was so hard to be a leader. If I said no, what if I was wrong? If I said yes, we might waste our strategic resources on nonstrategic opportunities. If that happened, would we still have become what we are today? Now it is your turn to lead the world, you will then feel what it's like to be raked over hot coals. (Ren Zhengfei: Scale New Heights and Forge Ahead into Uncharted Territory Along Multiple Paths in Multiple Waves-Key Messages of Discussions at Mobile World Congress and in Ukraine, Huawei Executive Office Speech No. [2016] 068)

\subsubsection{In Field Offices Are Highly Competent Lean Teams Dealing With Uncertainties; In Back Offices Are Functional Departments and Shared Services Centers Dealing with Certainties}

In the future, the company will become an organization composed of highly competent lean teams. We should focus on building such teams in field offices to deal with the uncertainties of technology, customer needs, transaction terms, and delivery terms. Operations with certainty should be handled by functional departments in regions. (Ren Zhengfei: Speech at the Briefing on the Progress of the Transformation Elite Team, Huawei Executive Office Speech No. [2015] 029)

When our field offices become light and agile, we won't have to pour our energy into routine matters any more, and our key operating teams can focus on their primary work. Our key operating teams must clearly describe needs. First, they must spell out customer needs so that our R\&D team can help meet them. Second, they must clearly state their needs for supply so that our back offices can provide support. Once these needs are clarified, everyone will know their own responsibilities, and it will be easy to measure performance. (Ren Zhengfei: Speech at the Briefing on the Progress of the Transformation Elite Team, Huawei Executive Office Speech No. [2015] 029)

Over the past two decades, IBM has helped us connect the dots, establish multiple platforms, and achieve rigorous, well-ordered development. In the next decade, we will need to change our operating model from large teams to highly competent lean teams to enhance the effectiveness, timeliness, and accuracy of our organization. We should allow such lean teams to deal with uncertainties and have our functional departments or 
shared services centers deal with certainties. When assessing the performance of departments that deal with uncertainties, we should focus on their ability to control risk. When assessing the performance of departments that deal with certainties, we should focus on their efficiency and results. During the transformation, we should place some command centers in field offices to enable those who are closest to customers to call for support. The purpose of this is to prevent our organization from growing too big and too bureaucratic. The $\mathrm{LTC}^{10}$ process has enabled us to identify customer needs. Back offices will become more capable in providing professional services and support. (Ren Zhengfei: Speech at the Meeting with Accenture Chairman Pierre Nanterme, Huawei Executive Office Speech No. [2015] 040)

In the future, our field offices will be made up of lean teams that deal with uncertainties, and our back offices will be made up of shared platforms that deal with certainties. We need to create certainty out of uncertainty and build a rational authority delegation and oversight mechanism, enabling those who are closest to customers to call for support. This will boost our overall operating capabilities and efficiency. (Ren Zhengfei: Speech at the Oath-taking and Awards Ceremony of the Transformation Elite Team, Huawei Executive Office Speech No. [2015] 047)

Lean teams are intended to deal with all kinds of uncertainties, including changing customer needs, transaction terms, and business environments. The key is to reduce our operating risks. Uncertainty in customer needs is primarily about marketing and R\&D. We spend so much money on them ever year, but much is uncertain. Uncertainty in transaction terms means our contractual situations are uncertain. At the moment, we can't even get our contract estimations straight. There are very few projects in which we submit bids based on clear estimations. For businesses of certainty, like delivery, service, finance, and supply chain management, we need to set up shared platforms. The key is to boost efficiency. When assessing our work in areas of certainty, we should focus on efficiency and results. (Ren Zhengfei: Speech at the Oath-taking and Awards Ceremony of the Transformation Elite Team, Huawei Executive Office Speech No. [2015] 047)

${ }^{10}$ LTC: Lead to Cash. It is a main business process at Huawei that spans from leads, sales, and delivery to payment collection. 


\subsection{Success Is Not a Reliable Guide to Future DEVELOPMENT}

\subsubsection{The Only Thing that Is Constant Is Change}

We are now in an era of rapid change in the IT industry. The only thing that is constant is change. If we hesitate to change, we will fall far behind. If we are happy with the status quo, and refuse to make progress or listen to criticism, it will be even worse. Should we head towards failure or even death to avoid losing face? Or should we correct our mistakes - without being scared of losing face - in order to catch up? To survive, we have to excel, and to excel, we have to move beyond our own limits, which requires promptly correcting all our mistakes. To achieve this, we need to be selfreflective. As Confucius said, "In a group of three people, there is always someone I can learn from." For Huawei, our competitor is one of these three people. The other two are our customer who speaks frankly about the issues of our products, and our subordinate who is frank and candid. We can correct any mistake we may have as long as we remain humble and open to criticism. (Ren Zhengfei: Why Do We Need Self-reflection?, 2000)

Greek philosopher Heraclitus said, "The only thing that is constant is change". Change is not terrible. It won't necessarily harm us if we keep working hard. This is a relative truth that we have always believed in and worked for. That's why Huawei has become what it is today. If our value assessment system - which advocates customer centricity, dedication, and perseverance continues to function and refine its own structure and form over time, it will gradually become less dependent on human intervention and will evolve into a new model - and an enduring system. No matter who leaves, our system will remain and evolve to an extent where it will no longer depend on human intervention. While people come and go, our system will persist. Relative truth continues to exist because of our tolerance towards it. (Ren Zhengfei: From "Philosophy" to Practice-Speech at Huawei Annual Management Conference 2011, Huawei Executive Office Speech No. [2011] 016)

Great changes have taken place in the business environment. We must think about how to adapt to these changes and promote transformations accordingly. Technology has changed significantly as well, from the era of voice to the era of broadband and on to the era of information. The size of the future market that these changes will create is beyond our imagination. Take cloud computing as an example. We have no idea how broad and deep its impact will be, nor can we foresee clearly what the future has 
in store. What will the future information society look like? It is impossible to design a perfect business model for this. (Ren Zhengfei: Success Is Not a Reliable Guide to Future Development, Huawei Executive Office Speech No. [2011] 004)

\subsubsection{We Are the Only Ones Who Can Defeat Ourselves}

Crises always lurk behind prosperity. But a crisis is not an inherent part of prosperity; it is something people feel in a booming environment. Hard work will eventually lead to prosperity. However, as soon as people are no longer dedicated, prosperity will inevitably fade. History is full of rises and falls. It is a mirror from which we can learn everything. If we forget the hardships we have been through, we are abandoning Huawei's culture. (Ren Zhengfei: Standing Against Pride and Complacency and Being Mentally Dedicated, 1996)

Who is likely to defeat us? Not others, but ourselves. If we fail to evolve, improve our management, and carry on our tradition of dedication, we will be defeated by ourselves. History is rife with examples of companies that succeeded for a time but failed to sustain their success. The DNA of failure is often embedded in success. We can set the pace only when we maintain a sense of urgency and create a drive for proactive innovation and adaptation to the future. (Ren Zhengfei: Toasting Those Who Succeed and Offering a Helping Hand to Those Who Fail, 1997)

A long, peaceful time and too many promotions may turn out to be a disaster for Huawei. The Titanic set off with a fanfare of hurrahs, didn't it? (Ren Zhengfei: Spring of Northern Country, 2001)

The past successes of hi-tech companies are often the mother of their failure. In this rapidly changing information society, only those who remain vigilant can survive. (Ren Zhengfei: Spring of Northern Country, 2001)

A group of Executive Master of Business Administration (EMBA) students from the School of Business at Renmin University of China visited Lancaster University in the UK. They were deeply impressed by the glories of Britain's industrial revolution and the UK's current development. One of them mentioned Huawei and some other leading Chinese companies to a British professor. The professor said, "Huawei is walking on a road which some famous companies in the world have once traveled. They were glorious at one time. Before reaching their peak, they stayed customer-centric and worked hard. However, when they reached the top, they started to become conservative and refused to listen to customers. As a result, they 
declined." I think this professor made the right historical observation: $\mathrm{He}$ foresaw what a company would eventually become if it evolved on its own. I once recommended an article listing defectors who had once been loyal to a certain undertaking. And where are the big fish who were once heavyweight players in the 1980s when China was reforming and opening up with vitality? Everything in the world is changing. And we are already left behind even without our awareness of it. (Ren Zhengfei: From "Philosophy" to Practice-Speech at Huawei Annual Management Conference 2011, Huawei Executive Office Speech No. [2011] 016)

Recently, we have been encouraging middle and senior managers and manager candidates to study the company's management culture outline, which summarizes the elements that have inspired us to remain dedicated over the past two decades. This outline was put together by the editorial board and other relevant personnel. It will be the eternal beacon that forever illuminates our path forward. But we need to understand our culture correctly; otherwise, overreliance on our past successes will cause us to go down the wrong path. (Ren Zhengfei: Success Is Not a Reliable Guide to Future Development, Huawei Executive Office Speech No. [2011] 004)

Are we going to be left behind by the times? Can we afford to be left behind? These are important questions. Many great inventors failed to expand on their initial successes. These include Marconi, who was the first to use radio waves for wireless telegraphy; Motorola, a pioneer in cellular communications; Lucent, inventor of optical transmissions; and Kodak, creator of the world's first digital camera. They failed because they didn't see the future clearly, or because they didn't have the courage to reinvent themselves or give up their vested interests when they did. Large companies have their advantages, but if they fail to keep pace with the times, they will vanish in the blink of an eye. The way forward in this new era may not be a straight path. Even light bends. Some long-standing theories in economics may be upturned in the new era. Previously successful methods may not work anymore when applied in the new era. How can we adapt to the rapidly changing era? We made several mistakes in the past regarding major strategies, including in broadband and softswitching. We later had to play catch-up in these two areas. Given Huawei's size, it will be very dangerous if we don't have the courage to embrace the future in this fast-changing era. The future is full of uncertainty, and we might even need to overturn our own advantages accumulated over the years. Where will we end up if we refuse to embrace this future? The extent to which we understand and envision the future information world is too small. That's why I'm encouraging senior managers to attend more international conferences, drink a 
cup of coffee with others, and have idle chats with others. Through today's idle chats, we have come up with many good ideas, right? Google is a visionary company. Can Huawei look as far into the future as Google does? But I think this degree of foresight is not enough. We need to look much further than Google, in order to adapt to this era of change. We need to predict what the future will be like, catch up, lead the way, and avoid being left behind. Through adaptation, openness, gradual restructuring, and effective handling of customer needs - initiatives similar to what IBM has done - even a large company can be revived, and it won't necessarily fade away. (Ren Zhengfei: Speech and Comments at the Carrier Network BG's Strategy Retreat in Huizhou, Huawei Executive Office Speech No. [2012] 010)

\subsubsection{The Best Defense Is a Good Offense; Moving beyond Existing Advantages to Create New Ones}

China's "reform and opening-up" policy has delivered remarkable results, and a large part of this success is attributable to those who have frequently criticized the policy. These critics watched us in China closely and found fault with everything we did, urging us to do even better. What has enabled Huawei to become what it is today is continuous improvement. We criticize ourselves day after day and expose our own faults. In doing so, we become stronger. In the future, we must strengthen our continuous improvement and establish a Blue Team that is dedicated to challenging Huawei. Every department should have a Blue Team to challenge themselves. As it meets these challenges, our Red Team will become stronger. If the leader of the Blue Team is unable to challenge Huawei, he or she must not remain in the position. The reason is simple. A leader who is unable to challenge Huawei does not know its potential for development. Such a leader is incompetent and will not move forward if he sticks to what he already has. Managers who are unable to criticize Huawei have reached their ceilings and will no longer be promoted. In contrast, those who can criticize Huawei have broad vision and unique opinions, and only such people should be promoted. (Ren Zhengfei: Speech and Comments at the Strategy Retreat of the Business Process \& IT Management Department, Huawei Executive Office Speech No. [2012] 026)

The best defense is a good offense. We need to move beyond existing advantages to create new ones. If we fail to do so, sooner or later other companies will surpass us. We should communicate more with our competitors (e.g., Ericsson, Alcatel Lucent, and Nokia Siemens) at academic conferences, and form strategic partnerships with them in relation to industry 
standards and policies. This will enable us to adapt to the fast-changing world. (Ren Zhengfei: Speech at a Meeting with the GTS Network Planning and Optimization Team, Huawei Executive Office Speech No. [2014] 012)

In the past, we moved up the value chain by offering quality products at low costs. This was the only approach we could take. It strangled our Western peers and also dealt a heavy blow to ourselves. However, our American peers, like Google and Facebook, have always moved down the value chain with strategic innovations. Wi-Fi is in direct competition with LTE. Who knows what tricks our American peers will have up their sleeves? We need to play it by ear. There's no way we can work out tactics in advance to guard against our competitors. We have made all our strategies open. We can't succeed with defense only. We need to remain open, as this is the foundation for our future success. (Ren Zhengfei: Speech at a Meeting with the GTS Network Planning and Optimization Team, Huawei Executive Office Speech No. [2014] 012)

We need to keep our feet on the ground and engage in hands-on practice. We won't know which one of us will stand out from the crowd. We are a team of some 150,000 people, and I think someone will step up and lead us to success, though I don't know who he or she is right now. I place my hope in you, and I expect you to take on your responsibility. (Ren Zhengfei: Speech at a Meeting with the GTS Network Planning and Optimization Team, Huawei Executive Office Speech No. [2014] 012)

Open Access This chapter is licensed under the terms of the Creative Commons Attribution-NonCommercial-NoDerivatives 4.0 International License (http:// creativecommons.org/licenses/by-nc-nd/4.0/), which permits any noncommercial use, sharing, distribution and reproduction in any medium or format, as long as you give appropriate credit to the original author(s) and the source, provide a link to the Creative Commons licence and indicate if you modified the licensed material. You do not have permission under this license to share adapted material derived from this chapter or parts of it.

The images or other third party material in this chapter are included in the chapter's Creative Commons licence, unless indicated otherwise in a credit line to the material. If material is not included in the chapter's Creative Commons licence and your intended use is not permitted by statutory regulation or exceeds the permitted use, you will need to obtain permission directly from the copyright holder.

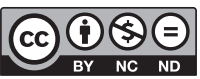

